\title{
A Biograficidade em Curso: Como os professores se tornaram professores
}

\author{
Unfolding biograficity: as teachers becomed teachers \\ Denise Figueira-Oliveira (denfioli@gmail.com)
}

Pós-doutoranda PROPEC/IFRJ

Maylta Brandão dos Anjos (maylta.anjos@ifrj.edu.br)

Docente PROPEC/IFRJ

Giselle Rôças (giselle.rocas@ifrj.edu.br)

Docente PROPEC/IFRJ

Resumo: Com o objetivo de compreender aspectos da formação de professores, apuramos a escuta sobre relato de professores que cursaram um mestrado acadêmico em ensino de ciências. Esse exercício possibilitou estabelecer uma conversa sobre suas narrativas pautadas nos princípios da memória social, percebendo o quanto o movimento de se repensar atende a convocação permanente que a Educação nos faz enquanto seus agentes. Pautados em uma pesquisa de cunho qualitativo, as narrativas foram colhidas e reelaboradas com inspiração na técnica do Ateliê Biográfico, sendo os dados coletados analisados à luz do referencial teórico apresentado. Três categorias emergiram da análise, sendo elas: professor(a) em formação, professor(a) em transformação e professor(a) em conformação. As narrativas nos enriquecem em possibilidades de olhar e interpretar a história em vidas de professores já formados, fornecendo elementos que devem ser considerados para pensar a formação inicial e continuada de professores.

Palavras-chave: formação de professores, narrativas, memória social, ensino de ciências, ateliê biográfico

\begin{abstract}
In order to understand aspects of science education, we listened teachers' reports who attended an academic master's degree in science education. This exercise made it possible to establish a conversation about their narratives based on the principles of social memory, realizing how much the rethinking movement meets the permanent call that Education makes us as its agents. Based on a qualitative research, the narratives were collected, and the analysis were based on the technique of the Biographical Studio, and the collected data were analyzed in the light of the theoretical framework presented. Three categories emerged from the analysis, namely: teacher in training, teacher in transformation and teacher in conformity. The narratives enrich us with possibilities of looking and interpreting life-histories of these teachers who have already graduated, providing elements that must be considered to think about the initial and continuing teacher education.
\end{abstract}

Recebido em: 23/03/2020

Aceito em: 08/07/2020 
Keywords: science education, narratives, social memory, science education, biographical studio

[...] eи comecei a fazer Biologia porque eu achei que pudesse salvar o mundo, nadar com golfinhos, tartaruga... mas aí eu acordei porque precisava de dinheiro e foi isso, eu comecei a dar aula, nunca gostei de dar aula, tenho dez anos de sala de aula-Professora de ciências do EF2.

\section{INTRODUÇÃO}

"Eu queria pegar na semente da palavra", a fala de Manoel de Barros traduz o objetivo desse estudo, sendo as imagens poéticas manoelinas que deflagraram a desestruturação da linguagem, nos retiraram da monotonia do lugar comum, dando espaço para a palavra contar o que é necessário. E contar é toda a caminhada. Mergulhadas nos anseios do ensino, desarrumamos gavetas e arquivos simbólicos para uma tentativa de reinvenção, de resgate do que esse âmbito já apresentou de melhor para espelhar e recriar o lugar do professor nos dias de hoje, em um momento histórico e conturbado no cenário educacional brasileiro: uma demanda da construção de um profissionalismo renovado dos professores. A fala trazida em epígrafe, analisada pelo viés manoelino, mostra quantas escutas são possíveis para entendermos os professores que hoje atuam.

Compreender o contexto atual da Educação exige de todos nós o entendimento das transformações e exigências dessa profissão, permite que repensemos o modelo e dado ao forte questionamento das estruturas formativas e curriculares, busquemos aprimoramento para enfrentar o desafio de reconectar a formação às dimensões socioculturais vigentes (GATTI, 2013). Alguns estudos abriram caminho para o plottwist ou ponto de virada, que recupera para o centro do debate os professores por meio de atitudes reflexivas (GONÇALVES, 2004; NÓVOA, 2007 e 2015; SCHÖN, 2007; ALARCÃO, 2011; GALIAZZI, 2011; SOUSA, SILVA e BEDIN, 2020). E por onde começar? Sob qual perspectiva?

Para além do que sabemos sobre o Homo sapiens, Homo loquens e mesmo o Homo ludens, temos o Homo narrans (GONÇALVES, 1981; BARTHES et al 2011; RABATEL, 2016). Eis que nessa prática humana universal, a narrativa, condição adquirida por natureza, impulsiona um fluxo contínuo de reinvenção da realidade, quando esta parece ter chegado a um marasmo ou rua sem saída. O ato de comunicar-se, contar-se seja, para autocompreender-se, para apresentar-se ao outro, ou ainda, compreender a sociedade em que se vive, resgata a narrativa como um grande valor do nosso tempo.

A provocação do poeta apresentada por nós na epígrafe sugere alguns itinerários que costeiam a memória autobiográfica e coletiva de uma geração nascente de professores de ciências. Esse respeito a oralidade, essa semente da palavra, na dimensão em que ela se revela própria e também quando estampa a sociedade em que está imersa, foi o caminho escolhido para investigar as reflexões de professores em formação em um curso de mestrado em ensino de ciências, no IFRJ, campus Nilópolis. Escolhemos a vertente da narrativa, por meio de histórias de vida, como método de trabalho para desenvolver o estudo.

Recebido em: $23 / 03 / 2020$

Aceito em: 08/07/2020 
Josso (2004) ao trabalhar com as histórias de vida, assinala o exercício de leitura dessas histórias e da importância de se fazer também a escrita do outro. Inferimos, a partir do olhar da autora, que os pressupostos que inspiram à formação de professores pelas histórias de vida apresentam aspectos relacionados às narrativas das experiências que esses sujeitos fazem de si, de sua ação como profissional docente, de sua história de vida e dos processos de transformação pelos quais passam na sua formação e no seu fazer profissional. $\mathrm{O}$ processo de reconstrução nas narrativas empresta vigor à vida dos sujeitos que são convidados a contar suas trajetórias e a tecerem suas memórias, correlacionando os tempos históricos de forma representativa e significativa. Nóvoa (2007) também argumenta em favor da utilização de metodologias que partam das histórias de vida de professores de práticas de ensino e mesmo reflexão sobre a profissão docente, tema sobre o qual nos debruçamos.

Portanto, ao falar de história de vida, formação e memória, a narrativa, com o viés do Ateliê Biográfico (DELORY-MOMBERGER, 2006), logo nos toma como elemento de fortalecimento do processo de construção dos sujeitos professores, reacendendo um recontar de si, das ações feitas e da compreensão das práticas de formação docente. Nesse sentido, a narrativa faz com que os sujeitos retomem suas ações e práticas, de acordo com os espaços e os tempos numa singular ação de si.

Sob a inspiração inicial na técnica do Ateliê Biográfico cunhado por Christine Delory-Momberger, com características e aspectos ligados, a valorização da fala e a sofisticação da escuta, desenhamos o momento para acionar o passado, sentir o presente, associando a ousadia de projetar o devir. A dinâmica proposta pelo projeto de Delory-Momberger (2006) veio ao encontro dos estudos voltados para provocar a consciência do que vem a Ser professor em um contexto de reflexividade sobre a práxis desse profissional na atualidade (NÓVOA, 2015; ALARCÃO, 2011; SCHÖN, 2007 e GALIAZZI, 2011).

Esse entrelaçamento das falas que tecem e dão sentido as vidas decorrem de nossas práticas que de tempos em tempos clamam por revisão, ajustes, acompanhamentos, upgrades, enfim, movimentos pautados em um plano futuro para as investigações educacionais. A ação educativa está enraizada nessa relação do lugar dos agentes, contar o percurso, contar dessa relação com a profissão, seus trâmites e suas inspirações. Para tanto, optamos pelo diálogo para recriar esse espaço de fala, tendo em vista despertar além das memórias, o mundo sensorial que marcou suas trajetórias e contam um pouco de como optaram por serem professores. Dentre as diferentes contribuições esse movimento oferece o compartilhamento de ideias, caminhos percorridos e pontos de referência, são alcançados e/ou tangenciados, pois diante do processo histórico de escrever, ler, ouvir e reescrever suas próprias histórias facultado ao sujeito a possibilidade de (re)inventar novas possibilidades. Assim,

a linguagem foi com frequência identificada à razão, ou à própria fonte da razão. Mas é fácil perceber que essa definição não consegue cobrir todo o campo. É uma pars pro toto; oferece-nos uma parte pelo todo. Isso porque, lado a lado com a linguagem conceitual, existe uma linguagem emocional; lado a lado com a linguagem científica ou lógica, existe uma linguagem poética. Primariamente, a linguagem não exprime pensamentos e ideias, mas sentimentos e afetos (CASSIRER, 1994, p.49).

Recebido em: $23 / 03 / 2020$

Aceito em: 08/07/2020 
Neste artigo, apresentamos a discussão dos resultados de uma pesquisa narrativa, de cunho qualitativo, considerando as histórias de vida de professores matriculados na disciplina Formação de Professores nos anos de 2017, 2018 e 2019, objetivando mostrar quantas escutas são possíveis para entendermos os professores que hoje atuam. Ao analisarmos os resultados, as falas dos professores, entendemos que eles iniciaram suas práticas docentes impulsionados pela necessidade contextual, no sentido contrário do princípio marxista, quando as necessidades e desejos devem reger o trabalho, as inclinações, as habilidades e aptidões (BENJAMIN, 2003). Os depoimentos revelaram o recorrente, por necessidade, dito pelos professores em formação continuada como carência de alternativas e limitação de outras possibilidades profissionais durante suas formações iniciais, nesse caso as licenciaturas.

Apoiadas na apresentação de um dispositivo inspirado nos Ateliês Biográficos, buscamos identificar, sob recorte, o perfil profissional do professor que atua no cotidiano da educação brasileira, pública ou privada. Avaliamos ser esse um procedimento que inscreve a história de vida em um arrojado cenário que liga $o$ passado, o presente e o futuro do sujeito professor em formação, com vistas a fazer emergir o projeto profissional, a traçar o perfil, considerando a dimensão do relato como construção da experiência desse sujeito ao construir a sua história de vida, como registro de sua formação de memória.

\section{O PERCURSO METODOLÓGICO}

Apoiadas nos pressupostos de uma pesquisa qualitativa do tipo participante (BRANDÃO, 1984) buscamos uma participação mais ativa e questionadora dos professores em formação envolvidos na pesquisa, tendo como intencionalidade resultados socialmente relevantes consideramos uma metodologia que nos desse acesso as suas vidas pessoais e profissionais. O dispositivo do Ateliê Biográfico proposto por Delory-Momberger (2006) foi um ponto de partida inspirador e acrescenta o estímulo aos participantes a produção de uma escrita autobiográfica, na qual optamos pelo percurso da narrativa e da escuta. $\mathrm{O}$ aluno 1 contava sua história, o aluno 2 escrevia essa biografia e o aluno 3 lia em voz alta essa biografia. E assim, a ciranda rodava, com todos ocupando cada uma dessas etapas.

Assim, os sujeitos da pesquisa foram mestrandos num curso de ensino de ciências, inscritos na disciplina de Formação de Professores em Ensino de Ciências, nos anos de 2017, 2018 e 2019, totalizando 21 participantes, convidados a participarem dessa atividade. Todas as etapas foram explicitadas e, após a concordância e assinatura do Termo de Esclarecimento e Livre Consentimento, as etapas a seguir foram desenvolvidas. Para preservar a identidade dos sujeitos, optamos pelo uso de códigos alfanumérico.

As narrativas foram gravadas em áudio e transcritas por nós, contrapostas com as narrativas redigidas em sala de aula, gerando novas perguntas específicas para cada caso. Os sujeitos da pesquisa foram então convidados pelas professoras, aproximadamente 30 dias após o término da disciplina, para responder (se confortáveis se sentissem para tal) as novas perguntas, após a escuta de suas próprias narrativas, além da leitura das narrativas reelaboradas pelos colegas. Essa segunda etapa foi interessante, pois permitiu a cada um deles retomar elementos da sua fala, relembrar os ditos,

Recebido em: 23/03/2020

Aceito em: 08/07/2020 
completar os não ditos (a partir de novas perguntas específicas), além de perceberem que nem sempre aquilo que focavam tanto em sua fala, foi por vezes menos percebido/destacado pelo colega que ouviu e redigiu a narrativa em primeira pessoa.

A análise dos dados coletados foi feita à luz do referencial teórico da formação dos professores reflexivos (NÓVOA, 2015; ALARCÃO, 2011; SCHÖN, 2007) baseados no pressuposto das narrativas como instrumento para compreender a formação profissional desses sujeitos (GONÇALVES, 1981; DELORY-MOMBERGER, 2006) associadas a discussão da memória coletiva e individual (POLLACK, 1989; 1992). Leituras flutuantes foram realizadas, até que os dados fossem incorporados pelas autoras e as categorias de análise emergissem.

\section{TESSITURAS DO DIÁLOGO COM OS NOSSOS REFERENCIAIS}

Todas as etapas nos exigiram atenção ao pensamento por meio da fala, da escrita e reinterpretação dos dados colhidos. Nos importou nessa análise as narrativas, ainda que tenham escapado para a imaginação, emocionais, fantasiosas ou dramáticas. As narrativas embebidas no relato das histórias de vida deram esse retorno de valorização do conhecimento direto e indireto produzido pelos participantes e interpretado por nós nas diferentes linguagens experimentadas (visual, verbal, corporal, sonora, digital). Um olhar sobre todo o processo desnudou o processo cognitivo e gnosiológico que a nossa criatividade tornou possível. A narratividade desse grupo ganhou feições ambíguas, de ideias, incertezas, posicionamentos, auto responsabilização por um projeto pessoal de cada um deles.

Nos remetemos a Souza (2008), quando nos aponta o quanto podemos nos sensibilizar na qualidade de pesquisadoras acerca da construção das narrativas, que colocam os sujeitos em contato com suas experiências formadoras, com as suas memórias e histórias, desnudando expectativas e perspectivas de suas vivências e das subjetivações redundadas e construídas por elas. Efeito similar envolvendo a leitura e a escrita, uma prática que valoriza subjetividade de professores em formação está descrita no estudo de Cabral (2019) com a experiência junto a licenciandos considerando seus diários de bordo.

Um ateliê biográfico pauta-se nos fundamentos e procedimentos levantados em memórias e histórias de vida, e segundo Delory-Momberger (2006) a proposta de formação por meio de histórias de vida vai além da utilização dos saberes formais, extrapola o reconhecimento dos espaços e saberes da experiência. Ele soma todas as experiências e as reflexões sobre ela, história de vida, dita em pele, é sensação e fazer. Rever, reescrever-se. Nessa perspectiva, o Ateliê Biográfico, na voz da referida autora, trata de um procedimento dinâmico que lida com a dimensão temporal, ligando passado, presente e futuro na perspectiva dos sujeitos históricos e na contingência de fazer emergir o projeto pessoal e as possibilidades de futuras mudanças abertas de si para o mundo. Ainda que tenhamos nos inspirados na técnica, não a executamos conforme prescrito por Delory-Momberger, pois não dispúnhamos dos seis meses necessários para tal mergulho. Acolhemos, portanto as três etapas sugeridas por ela, possibilitando que cada sujeito experimentasse as três etapas previstas: fala, escrita e escuta. 
Fundamentadas no que podemos chamar de aproximação entre ação profissional na narrativa docente, observamos que o perfil desse profissional está ligado não somente a formação retratada pelos sujeitos investigados, mas sobretudo ao processo de apropriação dessa formação, que deve ser processual, contínua e capacitadora (NÓVOA, 2015). Assim (re)construir o perfil profissional do professor, seu processo formativo, por meio das suas narrativas, tem no reconhecimento - do saber e do fazer, suas práticas e experiências de vida, suas relações sociais e suas atividades que merecem ser revistas em memórias, histórias e saberes da sua formação (GONÇALVES, 2005; DELORY-MOMBERGER, 2006; GHEDIN e FREITAS, 2015). Após o mergulho nas narrativas, três categorias iniciais caracterizadoras do perfil desses profissionais emergiram após as diversas leituras e escutas: 1) Professor(a) em formação; 2) Professor(a) em transformação; 3) Professor(a) em conformação.

\section{PROFESSOR EM FORMAÇÃO, CONFORMAÇÃO E TRANSFORMAÇÃO}

Ao longo da experiência com professores e professoras foi possível constatar como as narrativas tecem as vidas humanas, ou ao menos constituem seus lugares de memória. Os mestrandos e mestrandas envolvidos nesse estudo, ao cumprirem o percurso da memória em sua pluralidade de funções, por meio da metodologia escolhida, ordenaram e deram sentido às suas trajetórias, como docentes atuantes e com alguma experiência, ou mesmo seu projeto docente enquanto iniciam a profissão. Esse exercício de pensar a prática, abrigou as lentes de Paulo Freire, dentre outros educadores-chave para a formação de professores no que diz respeito aos saberes fundamentais à prática docente, condição em que, pensar certo, envolve o movimento dinâmico, dialético, entre o fazer e o pensar sobre o fazer (FREIRE, 1996, p.43).

Os professores e professoras que participaram do estudo fizeram e entregaram, por escrito a descrição de suas trajetórias, que foram associadas a narrativa oral, devidamente autorizadas e transcritas por nós e aqui selecionadas para discussão do trabalho. O ambiente da sala de aula foi o mesmo no qual foram realizadas as releituras das histórias da vida profissional dos professores e professoras envolvidos.

A reflexão sobre os resultados obtidos pode ser descrita pontualmente aqui, entendendo que, o(a) professor(a) em formação é aquele(a)(s) que embora tenha direcionado a sua graduação nesse sentido, ainda não atua ou tem menos de três anos em sala de aula: Pemfor. Já o(a)professor(a)(s) em transformação aquele(a)(s) que tem alguma experiência em sala de aula, mas que em especializações e outros estudos e buscas de aprimoramento, reconhecem mudança na prática: Ptransfor. Convém aqui adiantar um exemplo desta a categoria identificada:

"A minha metodologia agora é diferente, as minhas aulas agora são diferentes das minhas aulas do início do ano. E eu vejo essa diferença nos alunos. Porque eu já chego em sala e eles falam assim, o que vai ser hoje?

Porque cada aula eu me reinvento. Até porque eu acho que esse é o objetivo. A professora que eu gostaria de ser é essa. E não me rotular, eu sou assim!!(enfática)

Recebido em: $23 / 03 / 2020$

Aceito em: 08/07/2020 
Porque como os alunos não são iguais eu não posso ser a mesma pessoa se eu quero tentar atender à todos. Então, a aula que eu dou hoje não pode ser a mesma aula que eu vou dar no ano que vem na mesma disciplina porque a turma não é a mesma. (P15- Ptransfor)",

Da experiência obtida ao ouvir os mestrandos de 2017, 2018 e 2019, foi identificada a terceira categoria, o(a) professor(a)(s) em conformação. Sob o rigor metodológico de leituras e escutas apuradas, tais profissionais parecem ou dão indícios de que não alcançaram sua vocação e permanecem lecionando por falta de espaço no mercado de trabalho ou por desconhecerem sua vocação mais orgânica: Pconform.

O movimento narrativo empreendido por nós, na disciplina Formação de Professores de Ensino de Ciências, sustentado na natureza das relações sociais promovidas em sala de aula, na opção metodológica, ou seja, no tipo de comunicação empreendida, bem como nosso alinhamento nos referenciais afins, tinha o objetivo de chegar o mais perto possível da trajetória de professores e professoras refletindo sobre suas respectivas práticas, reconhecendo seus processos identitários. A inspiração no método de Delory-Momberger (2006), Ateliê Biográfico, parece ter oferecido ambientes favoráveis a esse registro e valoração das experiências vividas por nós junto a esses profissionais, a fim de que conhecendo o contexto histórico, social e cultural vigente, mais chances tenhamos; como formadoras, de apresentarmos recursos de aprimoramento da prática docente.

Estimuladas ao debate sobre a significação das narrativas captadas, por meio das perguntas-chave do estudo que aqui registramos, nos cabe evidenciar os saberes já vivenciados e narrados na proposta feita por nós. Em resposta a primeira pergunta, Por que se tornou professor? Quem ou o que o(a) motivou?, concepções são apresentadas sob recorte e indicam como os participantes rememoram suas trajetórias:

“E o que me levou a ser professora, é uma história legal porque começa com três anos de idade que eu tinha, e a minha mãe me levava para a escola. Minha mãe era professora, era orientadora educacional em uma escola aqui em Quintino, na Rui Carneiro e por que ela me levava?

Porque a minha tia teve meu primo e meu primo era bebê e a minha vó não tinha como ficar com dois bebês em casa. Então, a minha mãe levava a $W$. pra escola. Onde é que iriamos colocar a F. na escola? Então me colocaram... não existia ensino de Jardim da Infância, então vamos colocar a F. na Alfabetização. É o único lugar, três anos de idade, grandona, mas ela cabe, vai passar despercebida. A diretora disse para a minha mãe, traga ela uniformizada, e aí minha me levou uniformizada e partir de então, eu passei a frequentar a escola e não consegui sair nunca mais!!(emocionada!). E eu não me lembro de me ver em outra profissão a não ser o magistério. (P12Ptransfor)'"

"O que me levou escolher a minha profissão foi ... eu não tinha vontade de ser professora, mas em dado momento, por necessidade, eu fiz formação geral, né? Porque eu tinha pavor de ser professora!!!

Por necessidade de precisar ganhar um dinheiro extra eu comecei a dar aulas particulares. E aí eu comecei a reparar o seguinte que, o retorno que meus alunos me davam despertou essa paixão. Porque eles chegavam para mim e falavam assim, mas $X$, eu não estava entendendo nada sobre isso, eu

Recebido em: 23/03/2020

Aceito em: 08/07/2020 
não conseguia, mas do jeito que você explicou eu consegui. Então, às vezes, eles traziam a matéria e diziam, a professora explicou, mas eu não entendi, mas sei que agora eu vou entender...então eu vi que conseguia fazer a diferença. (P19-Pconform)",

"A minha mãe fala que eu cuspi para o alto porque eu falei para ela que jamais seria professora. Fui criada na escola, numa família de educadores. Minha mãe e minha madrinha são professoras, alfabetizadoras. Eu cresci nesse ambiente e falei que daquela fonte eu não beberia...fui para faculdade para fazer bacharelado em Biologia, quando estava me formando eu vi que não tinha emprego e a minha mãe falou que eu tinha que me sustentar porque ela não ia viver pra sempre, me inscreveu no concurso da prefeitura e falou, vai lá e faz a prova. Eu fiz a prova, passei e não tinha Normal. Tive a oportunidade na universidade de pedir re-ingresso e fazer a licenciatura. Fiz a licenciatura porque eu me formei dentro dos quatro anos pra isso. Fiz um pós-médio à noite, porque a faculdade era integral, para conseguir entrar antes de ser chamada no concurso. Aí fiz prova pro Estado, porque eu me empolguei, passei em um, vou fazer outro...aí fui chamada no Estado e no mês seguinte eu fui chamada na prefeitura, e comecei a dar aula no ensino fundamental nos anos finais de $6^{\circ}$ ao $9^{\circ}$... ao mesmo tempo que eu dava aula pra $4^{\circ}$ e $5^{\circ}$ ano. (P15-Ptransfor)'”.

"Eu comecei a fazer Biologia porque eu achei que pudesse salvar o mundo, nadar com golfinhos, tartaruga... mas aí eu acordei porque precisava de dinheiro e foi isso, eu comecei a dar aula, nunca gostei de dar aula, tenho dez anos de sala de aula... (P13-Pconform)".

Se tomarmos por base o pensamento de Paulo Freire (1996) sobre o ensino com criticidade, observamos ao longo da experiência com os envolvidos no estudo, o olhar para si como forma de compreensão da constituição de suas respectivas identidades. Nós, sob a "inquietação indagadora", identificamos que, o contraexemplo também aparece como elemento de motivação de alguns professores escolherem essa profissão, ou seja, ao mesmo tempo em que descobrem inclinação para a profissão elaboram um pensamento mais crítico, elegem uma atuação inversa àquela que tiveram enquanto alunos. Essa correlação evidencia a complexidade dos múltiplos sentidos que envolvem o ensinar e o aprender. Nas palavras de Nóvoa (1995, p.17): a maneira como cada um de nós ensina está diretamente dependente daquilo que somos como pessoa quando exercemos do ensino.

Acolhidos pelo rigor do método proposto por nós, mestrandos e mestrandas articularam de forma consciente, fatos ocorridos, memórias, enfim, dimensões emocionais e cognitivas que permitiram a reorganização de suas trajetórias e tornaram possível revelar em detalhes o impulso que os conduziram à carreira docente, como podemos compreender na fala a seguir:

\footnotetext{
"Eu fiz o ensino médio técnico e o meu técnico em metrologia me mostrava todas as manhãs um ensino normal, assim como todo mundo tem no regular, $e$ à tarde eu tinha as disciplinas da parte técnica. As disciplinas da parte técnica eram ministradas dentro de um instituto de pesquisa. E eu não conseguia entender a diferença que tinha entre, aquilo que eu estudava nos livros, e, aquilo que eu tava vivendo dentro do centro de pesquisa. A partir desse momento me começou gerar uma inquietação onde eu poderia ter uma aproximação entre aquilo que eu vía em sala de aula, e o que eu vía na vida real. A partir desse momento eu pensei, eu quero tentar ser uma pessoa que possa aproximar esses dois ambientes. Nesse momento, eu decidi que eu
}

Recebido em: 23/03/2020

Aceito em: 08/07/2020 
gostaria de ser professor. E a escolha que eu tentei seguir foi a partir da minha especialização na área técnica. Eu acabei seguindo para aprofundar meus estudos em Física, onde me graduei na UFRJ em licenciatura em Física. (P 10-Pemfor)".

Inseridas nesse movimento socioeducativo que visa compreender melhor o ofício docente, nos alinhamos à visão de Estrela (2010) quando destaca a "natureza delicada e complexa" da profissão e que, "certamente nunca existiram épocas em que fosse fácil exercê-la", o que torna imperioso saber com quem e para quem produzimos reflexões e metodologias para auxiliar esse lugar e sua função social na sociedade em constantes mudanças em que vivemos. A globalização instaurada em nosso tempo ganha contornos específicos na formação de professores, na medida em que é preciso saber lidar com as ideias emergentes, as tecnologias avançadas e expectativas sociais que modificaram as competências.

Diferentes estudos apontam a vida do professor, essa não pode ser reduzida ou considerar apenas as suas dimensões racionais, objetivas ou somente o ponto de vista teórico e conceitual (NÓVOA, 2007; ESTRELA, 2010), eis porque trazemos, por meios de seus próprios exemplos, as dimensões afetivas, entre fragilidades e potencialidades em viva-voz. Assim, instigados pela pergunta-gatilho sobre que tipo de professor(a)(s) gostaria(m) de ser foi possível perceber que ainda há professores que mantêm presente o envolvimento com a prática educativa o idealismo, como podemos observar nas falas a seguir:

“...eu gostaria de ser uma professora que tivesse tempo de me dedicar mais aos meus alunos, gostaria de ter um espaço maior, um reconhecimento maior, por parte não só da sociedade, mas por parte instituição que eu trabalho também. E se eu pudesse, né... gostaria de ser também aquele professor que motivasse os alunos a aprender cada vez mais. É claro que a gente sabe que tem aluno que não vai além do que a gente ensina, mas aquele que gostariam de ser ...eu gostaria de ser aquela professora que fosse ajudar, que fosse tipo um degrau para o sucesso dele (P12- Ptransfor)'”.

Nesse momento, eu quero ser esse professor motivador. Um professor que desperta a curiosidade porque eu sou uma pessoa curiosa!! Em sala de aula, eu tento ser afável, brincalhão, tentando criar um ambiente seguro e amistoso pra que todas as pessoas possam tentar colocar suas dúvidas, suas curiosidades, e isso sem tentar sofrer represálias, sem tentar se esconder por qualquer motivo nesse momento (P10-Pemfor)'”.

"Eu gostaria de ser uma professora que refletisse sobre a minha prática sempre, que fosse algo constante, porque aquilo que a gente aprende ao longos dos anos que a gente se aprimora e que estuda, quando a gente vai para a prática a gente vê que, nem sempre está atendendo... às vezes, atendia ontem, mas hoje não atende mais, então, eu quero ser uma professora reflexiva, que eu esteja sempre refletindo sobre a minha prática para ver se ela está atendendo às necessidades do meu aluno, naquele momento. Também quero ser uma professora que dê voz aos alunos, que os alunos se sintam confortáveis com a minha presença, e que eu possa fazer a diferença na vida deles, de alguma forma, para melhor.

É.. pretendo ser, quando eu estiver na minha área, ser uma professora dedicada, colocar em prática tudo que eu venho aprendendo, pra tentar fazer da melhor forma essa Educação que a gente vê que tá tão precarizada, tão...

Recebido em: 23/03/2020

Aceito em: 08/07/2020 
sucateada, tentar melhorar. Eu sei que eu não vou salvar a pátria, mas acho que se cada um fizer um pouquinho, da melhor forma, a gente melhora a situação da Educação no nosso estado, no nosso país. O que levou a ser professora foi isso! (P18 - Pemform)".

Como um desdobramento fértil da experiência relacional empreendida nesse estudo, as narrativas e suas reflexões ultrapassaram o espaço das questões indagadas criando um espaço para categorias emergentes, reconhecidas por nós como: visão positiva de sua prática, a prática ensina e um lugar para chamar de meu: o papel do reconhecimento ao longo da prática.

As falas experienciais e relacionais obtidas com atividade proposta por nós para rever o passado no presente para transformar o futuro, vai ao encontro aos novos anseios da profissão-professor apontada, no início desse texto, como um dos desafios da cena educacional contemporânea. Nessa empreitada de atenção histórica e social da natureza humana, também consta a esperança, talvez advinda de uma visão positiva da própria prática, como é possível observar a seguir:

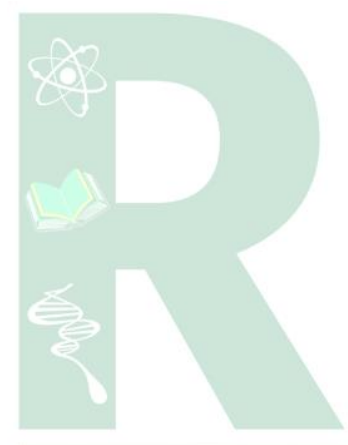

"Eu tento ser a professora que gostaria de ser. Eu passo tempo, eи me dedico, tenho assiduidade, eu sou pontual, eu tento levar o aluno a buscar o conhecimento, dar à luz para aquele aluno, através de atividades não muito ortodoxas, como, simplesmente, convidar o aluno para ir a ao museu de ciências de história natural. Para meu espanto, muitos dos graduandos da área de saúde, não conhecem o museu de história natural. Assim, de cinquenta você tira um ou dois que foram ao museu de história natural. Que foram à Fiocruz, às vezes, zero, que foram ao museu da Fiocruz. Então, assim... eu peço essas atividades para eles como forma de avaliação. Então, eu sou assim, aquela professora que é chata, nesse sentido, de pegar no pé deles fazerem esse trabalho e ser uma forma de avaliação, porque "se não for cobrado "eles não irão (P12- Ptransfor".)

"Eu gosto da maneira como eu sou em sala de aula, eu gostaria de tentar manter essas características, mas... que professor eu gostaria de ser? Eu gostaria de tentar levar um pouco dessas características e tentar alcançar isso no ensino superior

...queria manter essa característica, de conseguir entrar em sala de aula e enxergar para cada aluno meu, conseguir entender as histórias e... conseguir manter o espírito alegre, mesmo... sei lá, a juventude de sala de aula que me acompanhasse, mesmo não sendo assim tão jovem. E isso tudo acompanhado de uma credibilidade institucional, a ideia de que quando a gente é muito jovem, ninguém percebe que talvez, o que a gente está trabalhando é só uma forma de aproximação, mas que isso possa ser reconhecido como algo válido.

E por fim, a última característica que eu gostaria de tentar ser reconhecido pelos meus alunos, é que eu seja uma pessoa inspiradora. Se eu for considerado como alguém inspirador eu cumpri a minha missão. (P10Pemfor)'”.

"Então eu sou uma professora que estuda, que busca, que se descabela, que fica louca, mas que ... tenta da melhor forma ajudar aquele aluno, às vezes, fazendo mais do que eu poderia e eu gostaria de ser... melhor. Que melhor? Não sei, estou buscando ainda, estou tô tentando...tô seguindo. Mas acho que ainda tenho bastante tempo...sou feliz, a lá, cuspi pro alto caiu na minha

Recebido em: 23/03/2020

Aceito em: 08/07/2020 
cara, mas eu sou muito feliz (enfática). Não me arrependo de ter escolhido ser professora tanto que estou fazendo mestrado em Educação. (P15Ptransf)".

O interesse nas histórias da vida profissional desses mestrandos foi guiado pelos objetivos ligados à teoria, à prática e à desejada emancipação, como pensamos a formação docente. Nesse processo de reconhecimento que recuperou saberes e posicionamentos de educadores em aprimoramento, não podíamos deixar de destacar, narrativas desse percurso e a percepção de que a prática ensina, a saber:

“... trabalhando nesse centro de pesquisa, que também tinha as ações de ensino, eu tive uma docência antecipada. Isso me fez começar a entrar em sala de aula, com toda aquela motivação, todos aqueles pressupostos que eu tinha, e começar a fazer isso de forma errada. E... o bom é que eu consegui encontrar alguém que me levou a ser esse professor que hoje eu tento ser. Eu lembro quando tive uma disciplina de instrumentação pro ensino, uma professora, ela tentou ensinou muito, as bases de que a gente deveria tentar trabalhar e treinou com a gente em sala de aula, é... uma maneira correta de se dar aula, ou pelo menos uma maneira que não é correta de se dar aula. A

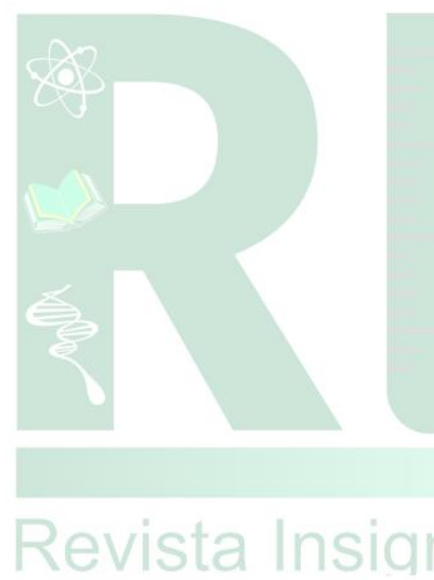
gente acabou aprendendo muito com os contra exemplos. E partir das avaliações que ela fazia, a gente tentava se aperfeiçoar e se aprimorar sempre. (P10-Pemfor)'”.

"Tive a oportunidade na universidade de pedir reingresso e fazer a licenciatura. Fiz a licenciatura porque eu me formei dentro dos quatro anos pra isso. Fiz um pós-médio à noite, porque a faculdade era integral, para conseguir entrar antes de ser chamada no concurso. Aí fiz prova pro Estado, porque eu me empolguei, passei em um, vou fazer outro...aí fui chamada no Estado e no mês seguinte eu fui chamada na prefeitura, e comecei a dar aula no ensino fundamental nos anos finais de $6^{\circ}$ ao $9^{\circ}$.... ao mesmo tempo que eu dava aula pra $4^{\circ}$ e $5^{\circ}$ ano. Foi uma loucura, porque como eu tive caminho da licenciatura ao inverso, eu não tive prática em momento nenhum, eu não tive essas aulas de didática em momento nenhum, porque eu estudava o dia inteiro. Ou eu estudava pra entrar no concurso ou eu fazia o estágio...E aprendi na marra, observando, olhando, aprendendo e tendo a experiência de vida que eu tive com a minha família. (P15-Pemtransfor)'”.

A análise da comunicação narrativa proposta na experiência de adaptação do Ateliê Biográfico, seus achados profissionais, suas emoções, revelaram processos de representação de realidades situadas historicamente nos ambientes narrativos fomentado por nós, que mediamos esse instrumento interpretativo. Os grupos em formação elegeram palavras, fatos e memórias transitórias no momento da experiência realizada (2017, 2018 e 2019). Sobre caminhos que nós formadores precisamos estar atentos, a categoria emergente, Um lugar para chamar de meu: o papel do reconhecimento ao longo da prática, deixa pistas:

\footnotetext{
"Ao contrário dos outros colegas, eu não me vejo fazendo outra coisa, então até quando eu tive uma crise de síndrome de burnout, de desistir de tudo, de partir para uma outra coisa aconteceu; nesse intervalo, uma outra coisa aconteceu que eu me re-apaixonei novamente pelo magistério. Eu ganhei um prêmio, onde os alunos me reconheceram como uma das melhores professoras da instituição. E eu ganhei esse prêmio e aí eu falei, então todos os meus esforços estão valendo à pena, aí eu me encontrei desde os meus três anos de idade. Então eu não sei fazer outra coisa (P12- Ptransf)".
}

Recebido em: 23/03/2020

Aceito em: 08/07/2020 
"a última característica que eu gostaria de tentar ser reconhecido pelos meus alunos, é que eu seja uma pessoa inspiradora. Se eu for considerado como alguém inspirador eu cumpri a minha missão. (P10-Pemfor)'”.

Perguntados como se fizeram professores, os mestrandos e mestrandas participantes recorreram a recomposição do passado e destacaram no tempo e no espaço outros elementos de como esse processo ocorreu, um exemplo:

“... Nem meu pai nem minha mãe tem faculdade, então assim, a minha mãe me deu muita força pra fazer faculdade. Quando eu terminei o ensino médio ela falou assim: Y. você vai fazer faculdade de todo jeito!

...Eu passei na Federal pra jornalismo. Eu sempre quis fazer jornalismo, só que quando eu terminei o ensino médio tava naquele período (...) teve uma polêmica que jornalista não precisava de (...) de diploma. Foi exatamente nessa época. Ai minha mãe falou assim: "Como é que você vai pra uma faculdade federal, lá eu vou ter muito mais gasto e você vai fazer uma faculdade que não vai adiantar de nada? Que qualquer outra pessoa que não vai ter formação vai poder trabalhar, vai poder exercer a função? Então foi um dos motivos que eu fiquei balançada também né, porque poxa, minha mãe tá fazendo um esforço danado pra me manter numa faculdade né, então ela teria que fazer um esforço muito maior pra tá aqui no Rio né. E eu gostava muito de biologia também... (P7-Pconform)".

Na visão de Delory-Moomberger (2006), a vida contada não é a vida, já que as histórias contadas têm como base, o mundo daqueles que as contam. Nesse mundo, estados intencionais, momentos estimulantes, bem como os de esvaziamento são partilhados em busca de credibilidade na interlocução entre, quem conta a história e quem ouve. Dessa forma, levamos em consideração que, as relações com as coisas e com as pessoas produzem sentido e adquirem função social para a narrativa.

Os depoimentos acima destacados assumem aspectos contextuais que antecedem a resposta à pergunta feita. Os participantes da biograficidade na sala de aula de uma pósgraduação construíram juntos suas significações.

\section{A GUISA DE UMA CONCLUSÃO: CONSIDERAÇÃO A PALAVRA COMO SEMENTE}

Quando estamos no meio da história, não é história de forma alguma. É só uma confusão, um bramido obscuro, uma cegueira. Destroços de vidro estilhaçado e lascas de madeira, como uma casa em um furacão, ou até mesmo um barco esmagado por icebergs ou levado pelas corredeiras e quem está de perto é capaz de impedir. Só em momento posterior torna-se algo parecido com uma história, quando estamos contando para nós mesmos ou para outra pessoa. ${ }^{1}$

As narrativas trabalhadas nesse artigo nos ofereceram surpresas ao ouvir e partilhar os momentos vividos na formação dos professores, nossos sujeitos narradores. Os quais ao falarem de si nos enriquecem em possibilidades de olhar e interpretar a história em vidas, opiniões e ações. Ao interpretar os contextos e as reinvenções de uma

${ }^{1}$ (Trecho do livro de Margareth Atwood, Vulgo Grace, 1991 - introdução do documentário História que contamos de Sarah Polley, 2012)

Recebido em: 23/03/2020

Aceito em: 08/07/2020 
história que não é só rica, não é só viva, é movimento em vida, mais verdadeiro e cheio de si.

Nesta perspectiva trabalhamos com três pequenos grupos de professores, totalizando ao final 21 docentes que retornaram à formação continuada em busca de algo mais. A busca os tem levado a formarem-se, transformarem-se ou conformarem-se. Por isso, no perfil profissional do professor, há que se pensar no que Murray (2001) nos falou: com delicadeza, se pode enxergar a alma, se pode adivinhar um anjo, se pode sentir o vento, se pode mudar o mundo com alguns pensamentos. Tentamos aqui trazer as palavras nas suas expressões de memória e histórias que retratam e põe em revista a própria vida no sentido do devir, da esperança do fazer e fazer-se sempre. Esse é o perfil, essa é a busca que não se encerra aqui, nos inspira e instiga a continuar pensando a formação de um professor, reconhecendo como profissional, com saber técnico e reflexivo. Por isso, consideramos a palavra como semente de todas as ações, fazeres, saberes ... transformações.

\section{AGRADECIMENTOS}

Agradecemos a todos os professores que aceitaram participar desde estudo confiando suas histórias a nós e aos colegas. Esperamos ter feito jus em nossa escuta ativa. Agradecemos a FAPERJ pelos recursos de apoio ao PROPEC (edital de apoio emergencial aos programas Stricto Sensu do Estado do Rio de Janeiro), à CAPES pela bolsa de Pós-Doc e ao IFRJ pelo fomento via edital Prociência que permitiu o desenvolvimento dessa pesquisa. Ao grupo de pesquisa CAFE - Ciência, Arte, Formação e Ensino pelas contribuições durante a análise dos dados.

\section{REFERÊNCIAS}

ALARCÃO, I. Professores reflexivos em uma escola reflexiva. Editora Cortez, 110p, 2003.

BARTHES, R; GREIMAS, A. J.; BREMOND, C.; ECO, U.; GRITI J; MORIN, V.; METZ, C.; TORODOV, T.; GENETE, G. A análise estrutural da narrativa. Introdução a edição brasileira por Milton José Pinto. $7^{a}$ edição. Petrópolis, Rio de Janeiro, Vozes, 2011.

BENJAMIN, C. Marx e o Socialismo. 2003.1ª edição.160p.

BENJAMIN, C. Marx e a Transformação Social. Busca em 14 de abril de 2019. Disponível em:

https://www.contrapontoeditora.com.br/arquivos/artigos/201202122245300.Marx\%20e $\% 20 \mathrm{a} \% 20$ transformacao\%20social.pdf.

CABRAL.W. A. O diário de bordo na formação de professores de química. Revista Insignare Scientia, v. 2, n. 2. Mai./Ago. 2019.

DELORY-MOMBERGER, C. Formação e Socialização: os ateliês biográficos de projeto. Educação e Pesquisa. São Paulo, v. 32, n. 2, p. 359-371, 2006.

BARROS, M. Memórias Inventadas: a infância. São Paulo: Planeta, 2003.

Recebido em: $23 / 03 / 2020$

Aceito em: 08/07/2020 
FREIRE, P. Pedagogia da autonomia: Saberes necessários à prática educativa. 30 ed. São Paulo: Paz e Terra, 2004.

GALIAZZI, M.C. Educar pela pesquisa: ambiente de formação de professores de ciências, Ed.Unijuí, 288p, 2011.

GATTI, A. B. Educação, escola e formação de professores: políticas e impasses.

Educar em Revista, Curitiba, Brasil, n. 50, Editora UFPR, out./dez. 2013, p. 51-67.

GONÇALVES, T.V.O. Metodologia da convergência: indivíduo, conhecimento e realidade: uma proposta para a formação de professores de ciências. Dissertação (mestrado). Universidade Estadual de Campinas, Instituto de Matemática, Estatística e Ciência da Computação, Campinas, São Paulo.1981. 233p. Disponível em:

https://repositorio.unicamp.br/bitstream/REPOSIP/306516/1/Goncalves_TerezinhaVali mOliver_M.pdf. Acesso em:12 ago. 2019.

GONÇALVES, T.V.O. Formação inicial de professores: prática docente e atitudes reflexivas. AMAZÔNIA - Revista de Educação em Ciências e Matemática, v.1, n.1, - jul./dez.2004, v.1, n.2- Jan/Jun.2005, p.73-79.

JOSSO, M. C. Experiências de vida e formação. São Paulo: Cortez, 2004.

MURRAY, R. Manual da Delicadeza de A a Z. São Paulo: FTD, 2001.

POLLAK, M. Memória e identidade social. Estudos Históricos, Rio de Janeiro, vol.5, n.10, 1992, p. 200-212.

POLLAK, M. Memória, esquecimento e silêncio. Estudos Históricos. Rio de Janeiro, Vol.2, n.3, 1989, p. 3-15.

RABATEL, A. Homo narrans: por uma abordagem enunciativa e interacionista da narrativa. Pontos de vista e lógica da narração, teoria e análise. v.1, Editora Cortez, São Paulo. 2016.

SCHÖN, D. Educando o profissional reflexivo: um novo design para o ensino e a aprendizagem. Porto Alegre: Artmed, 2007.

SOUZA, D. S.; SILVA, C. S.S. da; BEDIN, E. A relevância da observação na formação inicial docente vistas no desenvolvimento da prática reflexiva. Revista Insignare Scientia, v.3, n.1, Jan/Abr, 2020.

SOUZA, E. C. O conhecimento de Si, as Narrativas de Formação e o Estágio: reflexões teórico-metodológicas sobre uma abordagem experiencial de formação inicial de professores. In: ABRAHÃO, Maria Helena Menna Barreto. A Aventura

(Auto)biográfica: teoria e empiria. Porto Alegre: EDIPUCRS, 2006.

Recebido em: 23/03/2020

Aceito em: 08/07/2020 
Vol. 3, n. 5. Set./Dez.

ISSN: 2595- 4520
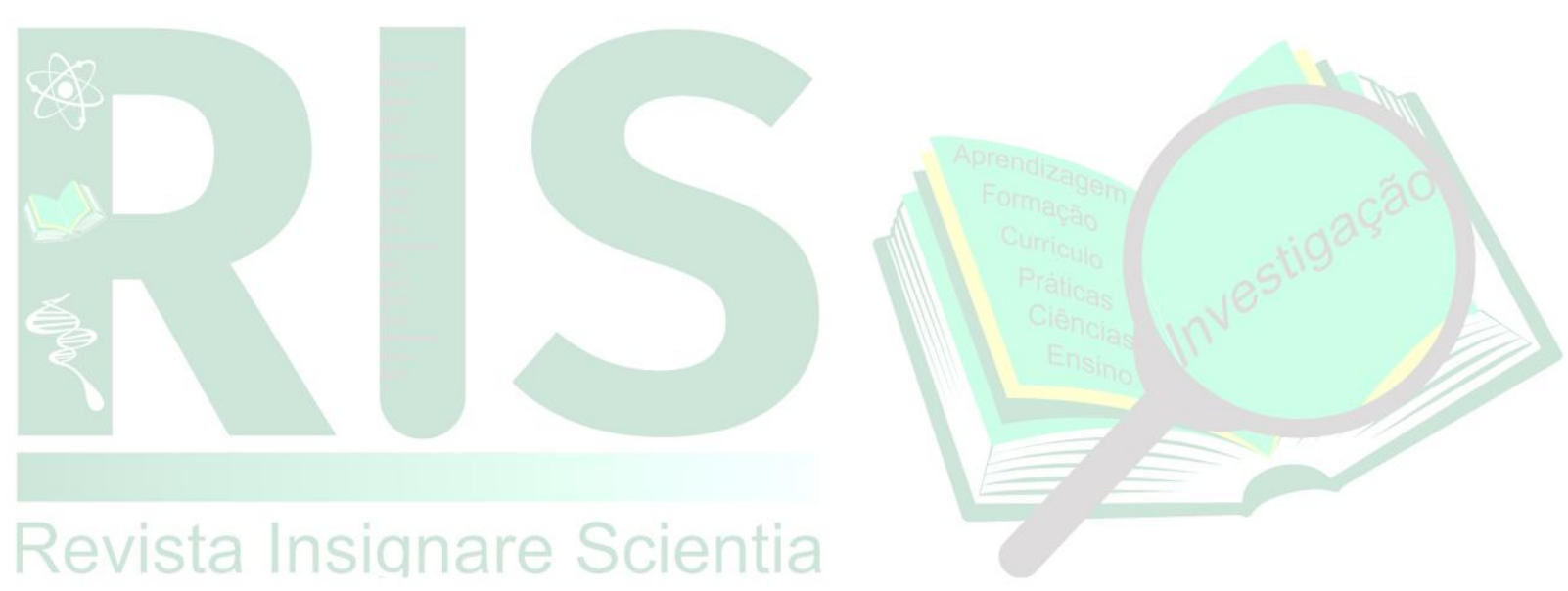

Recebido em: 23/03/2020

Aceito em: 08/07/2020 